\title{
Studies on preparation of karonda candy
}

\author{
RASHMI PATIL*, V.U. RAUT ${ }^{1}$ AND R.S. WANKHADE \\ University Department of Horticulture, Dr. Panjabrao Deshmukh Krishi Vidyapeeth, AKOLA(M.S.) INDIA \\ (Email: patilrashu03@gmail.com) \\ ${ }^{1}$ College of Agriculture, NAGPUR (M.S.) INDIA
}

*Author for Correspondence

Research chronicle : Received : 14.07.2014; Revised : 26.10.2014; Accepted : 12.11.2014

\begin{abstract}
SUMMARY :
An experiment on the studies on preparation of karonda candy was carried out during the year 2012-2013 at Post Harvest Technology Laboratory, Department of Horticulture, Post Graduate Institute, Dr. Panjabrao Deshmukh Krishi Vidyapeeth, Akola in Factorial Complete Ramdomized Design consisting of seven treatments and three replications with two drying methods (cabinet drying and solar drying). From the findings it was observed that, there was a gradual increase in TSS, titratable acidity, reducing sugars and total sugars content of the candy irrespective of drying methods and recipes used in experimentation. However, non-reducing sugars, ascorbic acid and moisture content of candy found to decreased with the advancement of storage period.
\end{abstract}

KEY WORDS : Karonda, Candy, Pectin, Vitamins

How to cite this paper : Patil, Rashmi, Raut, V.U. and Wankhade, R.S. (2014). Studies on preparation of karonda candy. Internat. J. Proc. \& Post Harvest Technol., 5 (2) : 136-140. 